\title{
Comprehensive Efforts Are Needed to Improve the Quality of Primary Diabetes Care in Korea
}

\author{
Chan-Hee Jung
}

Division of Endocrinology and Metabolism, Department of Internal Medicine, Soonchunhyang University College of Medicine, Bucheon, Korea

It is well known that comprehensive management of metabolic parameters such as hemoglobin A1c (HbA1c), lipids, and blood pressure is needed to reduce diabetes-related morbidity and mortality [1]. However, in Korea, many patients with diabetes do not meet recommended goals for diabetes control. According to the Korean Diabetes Fact Sheet, which used recent data from the Korea National Health and Nutrition Examination Survey (2013 to 2016), $25.1 \%, 68.4 \%$, and $44.2 \%$ of people with type 2 diabetes mellitus (T2DM) achieved an HbA1c less than 6.5\%, blood pressure less than $140 / 85 \mathrm{~mm} \mathrm{Hg}$, and a low density lipoprotein cholesterol level of less than $100 \mathrm{mg} / \mathrm{dL}$, respectively [2]. Only $8.4 \%$ of people with T2DM displayed control of all three targets [2].

In addition, regular screening for the early detection and proper monitoring of diabetic complications is fundamental to high-quality diabetes care. In spite of this, according to an analysis of Korea's National Health Insurance Service database, the proportion of patients who underwent an annual fundus examination was only $30 \%$ in 2013 [3]. This indicates that more than two-thirds of patients with T2DM did not have their fundus checked for at least a year. In another nationwide survey conducted in Korea, only $36.3 \%$ and $40.5 \%$ of patients received screening for diabetic retinopathy and nephropathy, respectively [4]. A study investigating geographical variation in the quality of care for T2DM in 2014 showed that during that year, only approximately $3 \%$ and $15 \%$ of patients underwent an eye exam-

Received: 9 September 2019, Accepted: 11 September 2019

Corresponding author: Chan-Hee Jung

Division of Endocrinology and Metabolism, Department of Internal Medicine, Soonchunhyang University Bucheon Hospital, Soonchunhyang University College of Medicine, 170 Jomaru-ro, Wonmi-gu, Bucheon 14584, Korea

Tel: +82-32-621-5158, Fax: +82-32-621-5016, E-mail: chanh@schmc.ac.kr ination and a microalbuminuria test, respectively [5]. Of note, these studies combined data from primary care and more specialized hospitals.

The burden of non-communicable chronic diseases continues to increase worldwide, and a paradigm shift has taken place from a focus on treatment to a focus on prevention [6]. Primary health care has been adopted as a key part of this strategy, and efforts for its reinforcement are being made all over the world. Several studies have shown that appropriate management by primary physicians improved glycemic control and overall disease outcome and reduced complications in patients with T2DM $[7,8]$.

Regarding the increasing burden of non-communicable chronic diseases, Korea is no exception. The burden of chronic diseases has increased both because such diseases have become more widespread and because of the aging of Korean population. In particular, mortality due to diabetes was higher in Korea than in other countries that are part of the Organization for Economic Co-operation and Development (OECD) [9]. The hospitalization rate due to diabetes, which represents the primary medical care-based outcome of diabetes, was 281 per 100,000 population in 2015 in Korea; this was the second highest rate among OECD countries [10]. For these reasons, policies have been adopted to promote primary care for chronic diseases such as diabetes. The Korea Centers for Disease Control and Prevention initiated a community-based registration and management

Copyright $\odot 2019$ Korean Endocrine Society

This is an Open Access article distributed under the terms of the Creative Commons Attribution Non-Commercial License (http://creativecommons.org/ licenses/by-nc/4.0/) which permits unrestricted non-commercial use, distribution, and reproduction in any medium, provided the original work is properly cited. 
program for patients with diabetes and hypertension in 2007, and the Health Insurance Review and Assessment Service (HIRA) of Korea implemented a diabetes quality assessment program in $2011[11,12]$. The importance of primary care clinic-centered diabetes care can be emphasized even in numerical terms alone. According to the HIRA data in 2017, approximately $60 \%$ of patients with diabetes visited primary care clinics for diabetes management, and the proportion of those primary care patients who visited more than once per quarter was 93\% [13]. At tertiary hospitals, patients are often seen only every 3 months or less often. Therefore, it might appear logical to speculate that frequent visit to a primary care physician can lead to higher-quality diabetes care and better outcomes, but metabolic parameters may remain under significantly better control in patients who receive diabetes treatment in a primary care setting.

However, few studies have investigated the comprehensive performance of $\mathrm{HbA} 1 \mathrm{c}$ testing, lipid profiling, and screening for microvascular complications that include neuropathy in addition to nephropathy and retinopathy. In this issue, Seo et al. [14] investigated the overall status of diabetes control and screening for diabetic microvascular complications in patients with T2DM attending 191 primary care clinics and three tertiary hospitals in 2015 and 2016 in Korea. They found that the patients treated at primary care clinics had lower rates of achieving all three metabolic targets, with a rate of $5.9 \%$ compared to $21.5 \%$ for those who received care at the three tertiary hospitals. The screening rates for nephropathy, retinopathy, and neuropathy within the past 12 months at primary care clinics were $28.4 \%, 23.3 \%$, and $13.3 \%$, respectively [14]. These findings are consistent with those of other studies. In the United States, more than $90 \%$ of patients with diabetes receive care from a primary care physicians, and studies have shown that the quality of diabetes care is suboptimal $[15,16]$. A retrospective cohort study using the National Ambulatory Medical Care Survey (2012 to 2014) showed low adherence rates to the recommended standard of care, including an adherence rate of $31 \%$ for HbAlc measurement, a rate of $13 \%$ for albuminuria screening, and a rate of less than $10 \%$ for retinal or foot exams [17].

Substantial efforts have been made to improve the quality of primary care for chronic diseases including diabetes in other developed countries including the United States Comprehensive Primary Care Initiative, the British Quality and Outcomes Framework, the Australian Practice Incentive Program, the German disease management program, and approaches such as clinical reminders implemented as part of electronic medical record system [17]. The Korean government also has taken mea- sures such as implementing chronic disease management systems in clinics, instituting a payment model to incentivize the use of primary care, reducing the user charge for primary care for patients with chronic diseases, paying providers a patient referral fee for care coordination, providing feedback and publicly disclosing patient outcomes, and offering pay-for-performance quality incentives [13].

Another noteworthy aspect of the study conducted by Seo et al. [14] was their finding that the rates of patients who had not undergone screening for retinopathy and neuropathy at a tertiary hospital within the past 24 months were 39\% and 55\%, respectively, although only 312 patients from three tertiary hospitals in Seoul were included in that analysis. Additionally, only $21.5 \%$ of patients achieved all three metabolic target. A diabetes preventative quality assessment in 2017 revealed that the retinopathy screening rates were $52.8 \%$ and $62.8 \%$ at general and tertiary hospitals, respectively [13]. Diabetes specialists and physicians at larger hospitals should pay attention to these results, as their efforts will be required in order to improve comprehensive diabetes care. Moreover, medical care systems should be established to facilitate more frequent interactions between physicians and the easy referral of patients from primary physicians to specialists at larger hospitals in order to test for complications of diabetes complications. Physicians must wake up to avoid clinician inertia.

\section{CONFLICTS OF INTEREST}

No potential conflict of interest relevant to this article was reported.

\section{ORCID}

Chan-Hee Jung https://orcid.org/0000-0001-8988-0187

\section{REFERENCES}

1. Stolar MW. Defining and achieving treatment success in patients with type 2 diabetes mellitus. Mayo Clin Proc 2010;85 (12 Suppl):S50-9.

2. Kim BY, Won JC, Lee JH, Kim HS, Park JH, Ha KH, et al. Diabetes fact sheets in Korea, 2018: an appraisal of current status. Diabetes Metab J 2019;43:487-94.

3. Ko SH, Han K, Lee YH, Noh J, Park CY, Kim DJ, et al. Past and current status of adult type 2 diabetes mellitus management in Korea: a national health insurance service database 
analysis. Diabetes Metab J 2018;42:93-100.

4. Byun SH, Ma SH, Jun JK, Jung KW, Park B. Screening for diabetic retinopathy and nephropathy in patients with diabetes: a nationwide survey in Korea. PLoS One 2013;8:e62991.

5. Cho S, Shin JY, Kim HJ, Eun SJ, Kang S, Jang WM, et al. Chasms in achievement of recommended diabetes care among geographic regions in Korea. J Korean Med Sci 2019;34:e190.

6. International Diabetes Federation. Final comprehensive global monitoring framework for NCDs [Internet]. Brussels: International Diabetes Federation; 2017 [cited 2019 Sep 16]. Available from: https:/www.idf.org.

7. Furno M. The primary role: how the availability of primary care physicians affects diabetes care management. J Med Pract Manage 2014;30:139-43.

8. Morrison F, Shubina M, Goldberg SI, Turchin A. Performance of primary care physicians and other providers on key process measures in the treatment of diabetes. Diabetes Care 2013;36:1147-52.

9. Organisation for Economic Co-operation and Development. Health care quality indicators: primary care [Internet]. Paris: OECD; c2018 [cited 2019 Sep 16]. Available from: http:// www.oecd.org/els/health-systems/hcqi-primary-care.htm.

10. Organisation for Economic Co-operation and Development. OECD health statistics 2019 [Internet]. Paris: OECD; c2018 [cited 2019 Sep 16]. Available from: https://www.oecd.org/ health/health-data.htm.

11. Yang HG, Lee DH. Achievements and challenges in a community based registration and management programme for hypertension and diabetes. Public Health Wkly Rep 2015;8: 827-34.

12. Kim YJ, Chon S, Oh S, Woo JT, Kim SW, Rhee SY. Analysis of diabetes quality assessment findings and future directions for the appropriate management of diabetes in Korea. Korean J Intern Med 2019;34:125-36.

13. Health Insurance Review and Assessment Service. Comprehensive quality report on diabetes 2017. Wonju: HIRA; 2017.

14. Seo DH, Kang S, Lee Y, Ha JY, Park JS, Lee BW, et al. Current management of type 2 diabetes mellitus in primary care clinics in Korea. Endocrinol Metab 2019;34:282-90.

15. Renders CM, Valk GD, Griffin SJ, Wagner EH, Eijk Van JT, Assendelft WJ. Interventions to improve the management of diabetes in primary care, outpatient, and community settings: a systematic review. Diabetes Care 2001;24:1821-33.

16. Spann SJ, Nutting PA, Galliher JM, Peterson KA, Pavlik VN, Dickinson LM, et al. Management of type 2 diabetes in the primary care setting: a practice-based research network study. Ann Fam Med 2006;4:23-31.

17. Wu SS, Chan KS, Bae J, Ford EW. Electronic clinical reminder and quality of primary diabetes care. Prim Care Diabetes 2019;13:150-7. 